\title{
Por una dialéctica de la resistencia: de la melancolía a la utopía (Aproximación a Benjamin)*
}

\author{
For a dialectic of resistance: from melancholy to utopia \\ (Approach to Benjamin)
}
Por una dialética da resistência: da melancolia à utopia (Aproximação de Benjamin)

Fecha de entrega: 10 de febrero de 2012 Fecha de evaluación: 27 de abril de 2012 Fecha de aprobación: 13 de junio de 2012

Pablo Emilio Daza Velásquez

\section{Resumen}

El presente artículo, en primera instancia, presentará la melancolía como mirada redentora del objeto, es decir, en la distancia de un "mundo desalojado" se halla la disposición sublime del hombre frente a las cosas. En segundo lugar se expondrá el papel de este objeto, representado por la técnica en las relaciones que el melancólico, la figura de poder, establece con los otros y cómo estas resultan coercitivas. Al final

* Este artículo es resultado de la investigación realizada por el autor en la Maestría en Filosofía de la Pontificia Universidad Javeriana. Es una ampliación de la ponencia presentada en el XIV Congreso Internacional de Filosofia Latinoamericana, organizado por la Universidad Santo Tomás en junio de 2011.

* Magister en Filosofía de la Pontificia Universidad Javeriana. En la actualidad se desempeña como coordinador de publicaciones y corrector de textos en universidades de Bogotá. Correo electrónico: daza.p@javeriana.edu.co 
se concluirá con una exposición sobre una dialéctica que se instaura en la contradicción de ese carácter melancólico de la no-acción contemplativa y la acción de los otros como resistencia en la utopía de la redención del sí mismo. Esta última es una posibilidad deconstructiva de la "condición humana".

Palabras clave: melancolía, técnica, violencia, resistencia, utopía.

\section{Abstract}

Firstly, this article, shall present melancholy as a redemptive look of the object, that is, in the distance of an "evicted world" is found the sublime disposition of man against things. Secondly, it will present the role of this object, represented by the technique in the relationships of the melancholic, the power figure, establishes with the others and how these result coercive. Finally, it will end with a presentation about a dialectic that is established in the contradiction of that melancholic character of the no-action contemplative and the action of others as resistance in the utopia of self-redemption. The latter is a deconstructive possibility of the "human condition".

Keywords: melancholy, technique, violence, resistance, utopia.

\section{Resumo}

O presente artigo, em primeira instância, apresentara a melancolia como olhada redentora do objeto, ou seja, na distância de um "mundo desalojado" haja-se a disposição sublime do homem em frente das coisas. Em segundo lugar se exporá o papel deste objeto, representado pela técnica nas relações que o melancólico, a figura do poder, estabelece com os outros e como estas tornam-se coercitivas. Ao final concluir-se-á com uma exposição sobre uma dialética que se instaura na contradição desse carácter melancólico da não-ação contemplativa e da ação dos outros como resistência na utopia de redenção em si mesma. Esta última é uma possibilidade desconstrutiva da "condição humana".

Palavras-chave: melancolia, técnica, violência, resistência, utopia. 
Solo a la humanidad redimida le concierne enteramente su pasado [...] Cada uno de sus instantes vividos se convierte en una citación á l'ordre du jour: este día es precisamente el día del Juicio Final.

Benjamin, 2007a, p. 66 Schelling descubrió, de manera análoga, la "esencia de la libertad humana", el indicio de la "simpatía del hombre hacia la naturaleza".

Kristeva, 1997, p. 12

\section{Introducción}

Quizá una de las formas más relevantes de resistencia sea el solo hecho de haber acuñado un concepto como el de "materialismo histórico", el cual nos desvela una construcción histórica desde la contemplación del objeto, una actitud materialista, que como lo explica Marx (s.f.), "solo concibe las cosas, la realidad, la sensoriedad, bajo la forma de objeto o de contemplación, pero no como actividad sensorial humana, no como práctica, no de un modo subjetivo". Así, evaluar la actitud del melancólico es adentrarse en una contradicción que es, al mismo tiempo, luz y oscuridad, genialidad y destrucción, "condición humana".

En la Antigua Grecia, la "condición humana" estaba regida por la templanza, constituida en la mesotes (el justo medio) en la que se evidencia una cotidianidad poética elevada de la exaltación a los dioses. Estos vivían dentro de una esfera cerrada llamada "destino". El actuar pertenecía a un no-actuar determinado de la acción. Luz y oscuridad son el destino en la condición de la hibris, donde la sabiduría del oráculo, que en la caverna toma distancia del mundo, es mediadora entre hombres y dioses, con una ceguera de tal profundidad que exigía la muerte del otro en sacrificio de un dios.

Benjamin confronta la tragedia griega y el Trauerspiel, la primera como violencia mítica del sacrificio, y la segunda como evidencia de esa violencia mítica en la redención del otro con la muerte del tirano: violencia divina. Tal destino ha construido la historia de los vencedores con monumentos que sumergen al otro en el olvido, que crean un sueño inexistente que sepulta las ruinas del hombre y, por ende, la historia. 
Referir el estudio de la melancolía en la historia es encontrarnos con el hecho de que esta no es una enfermedad, sino una "condición humana", que en el tiempo ha tenido múltiples interpretaciones que se sostienen entre sí y no pueden excluirse (Klibansky et ál., 1991). Desde su apreciación antigua, como base fundamental, se encuentra relacionada con el cuerpo, en concreto con su interior. Para Aristóteles, la melancolía, es decir, la bilis negra, es característica de una personalidad excepcional:

La "bilis negra" (melaina kole) que junto con la flema, la bilis amarilla (o "roja") y la sangre formaban el conjunto de los Cuatro Humores. Se creía que estos humores estaban en correspondencia con los elementos cósmicos y las divisiones del tiempo; que controlaban toda la existencia y la conducta de la humanidad, y, que, según cómo se combinaran, determinaban el carácter del individuo (Klibansky et ál., 1991, p. 29).

Asimismo, con Kant comprendemos que la mirada, por no decir el ojo, nos aproxima al exterior, la experiencia de conocer, como posibilidad inicial, a través de una impresión sensible del objeto. Pero, ¿dónde aflora la melancolía, ese carácter? A esto responde indirectamente, al decir que pese a que la experiencia empírica es nuestra primera forma de conocer, no es la única; además podemos adquirir conocimientos independientes de esta, porque estos son a priori. La melancolía se ubica en esta forma a priori de abordar los conocimientos empíricos que han retratado huellas en nuestro interior de forma a posteriori. Dentro del esquema kantiano, emitir juicios a priori es conseguir universalizar al margen de la experiencia; si esto se hace posible, el juicio es absolutamente a priori. Este absolutamente es expuesto no como la enfermedad del filósofo, sino como su propia naturaleza (ethos), posiblemente poética: la condición humana.

En este carácter del hombre, que por un lado es mítico y por el otro es histórico, se encontrará, de cierta manera, una posición poética y otra filosófica que, en este orden de ideas, constituirá la “condición humana”. Posiblemente, separarlas mostrará una contradicción, por no decir una opción contra natura. Por tanto, será encontrarse dentro de un "componente utópico" que desentierre la memoria y ponga de presente cómo la historia es una historia de la violencia, de un materialismo histórico que homogeneiza la mirada y se constituye en el olvido de los derrotados. 
La técnica ha sumergido al hombre en una profunda melancolía a la cual hay que resistir, pues nos envuelve en el olvido de lo inmediato. Este es el eje central del presente artículo: la melancolía y la resistencia dialogan alrededor de la "condición humana”. El hombre es en sí mismo poeta y filósofo, "condición” que estructura nuestro estar en el mundo en relación con la sublimación del objeto en la técnica y, posteriormente, lo espantoso del desconocimiento de su historia.

Por este motivo, se expondrá a continuación, en primera medida, el carácter mítico que "eleva” y representa al melancólico. Benjamin nos señala cómo aquel que redime al objeto del humor melancholicus - que emerge igual que la espuma del mar al chocar con las rocas- es triste y mezquino, de un temperamento colérico ante la posibilidad de la pérdida de lo deseado.

Seguidamente, se hará una breve exposición complementaria que pondrá en escena la melancolía en relación con el otro, en contraposición, al revelarse de esta una exaltación de lo estético en un hombre invadido por la genialidad (Aristóteles), que cuenta con una procedencia extraña, abisal, que se manifiesta en el deseo de poder. Esta contraposición construye la muerte y la define en la técnica, momento en el que el genio mítico sacrifica al otro; por otro lado, la deconstruye en la redención, cuando se le da muerte al tirano sin pretender el poder.

Finalmente se establece un diálogo entre esta melancolía, ahora violencia mítica, de la no-acción conservadora de un historicismo de los vencedores - que como diría Marx, expone un materialismo histórico que se olvidó del hombre- y la resistencia de los derrotados por no caer en el olvido, por hacer historia y escapar por un momento de ese estar arrojados a un lugar de desamparo. 


\section{La melancolía: redención del objeto en un mundo desalojado}

Odiado por los dioses erraba solo [Belerofonte] por el llano de Aleo, el corazón devorado por la tristeza y evitando las huellas de los hombres.

La Ilíada, VI, 200-203

El Trauerspiel nos muestra en el Origen del drama barroco la inmanencia de sus dramas en el reconocimiento de su actuar en un espacio-tiempo mundano, que tiene por objeto representar los personajes de una época. Por el contrario, en la tragedia griega se puede ver que existe una contraposición entre un tiempo del mundo y otro mítico, donde la lucha contra la divinidad se constituye trascendente: el objetivo es el mito.

La diferencia entre trascendencia e inmanencia consiste en su modo de lucha y en el grado de elevación de esta. En los dos dramas, la lucha se representa con la figura del héroe en contra de una especie de divinidad. La trascendencia se da en el momento en que la lucha marca un accionar del héroe, históricamente elevado, con una ruptura entre hombre y divinidad. En el Trauerspiel, la inmanencia aparece vinculada a la acción, por ejemplo, con Hamlet cuando da muerte al tirano que no-actúa por encontrarse en un estado enaltecido.

Ahora bien, antes de abordar la relación entre ese actuar y no-actuar, es indispensable exponer la figura que representa la no-acción, que está emplazada-desplazada en la distancia de lo absoluto y que hace "historia" al construir imágenes que representan una elevación memorable del pasado, de victorias sobre la muerte. La "condición humana" de violencia no deja ver otra cosa que la melancolía de los vencedores, que creen en la distancia no ser parte de un río de cadáveres. En la lejanía se piensa que las ruinas pertenecen a los vencidos.

El melancólico se retira a un "mundo desalojado", lugar de la no-acción, donde su mirada no concibe vivir bajo los parámetros de la simplicidad — sin preguntarse por aquello que constituye la fe- y donde la acción de la vida cotidiana le resulta imposible, pues no implica más que vivir rectamente. Para Benjamin es la misma actitud que conduce al luteranismo, el cual imagina la naturaleza con una complejidad desbordante. En esa elevación arrebata el efecto espiritual a las "buenas obras", vacío de lo místico, del amor por las pequeñas cosas. Hombres en depresión por el 
miedo a la muerte y, por tanto, la necesidad constante de preguntarse el porqué de la existencia en una profunda actitud de solemnidad. El luteranismo ha engendrado el luto en sus grandes hombres.

Por otro lado, la teoría de la melancolía también está relacionada con la astrología y representada por Saturno, quien en el cuadro Melancolía I de Durero aparece junto a elementos que simbolizan la distancia, se encuentra desalojado, es el astro más elevado debido a su belleza, pero el más lejano debido a su magnitud amenazadora. El melancólico prefiere los largos viajes, por eso la inmensidad del mar le resulta adecuada a sus meditaciones.

Saturno, el más triste de todos los melancólicos, cumple una función externa a la cotidianidad: es el retiro de los oráculos en la mitología y, con ello, el saber supremo. La melancolía pertenece al observador al dar vida al objeto de modo a priori, según la transformación que la mirada otorgue al objeto. Además concibe la sabiduría desde una contemplación que se convierte en una imagen onírica. Estos son los hombres de la meditación, pues existe en ellos una dialéctica de los opuestos en la que Saturno vela por lo divino y a la vez por lo bestial.

El Trauerspiel lo expone con la redención del objeto simbolizado en el trono, el cual posibilita al soberano una vida en la complejidad, solo accesible para él, donde en la soledad puede ser invadido por un espíritu que cuestiona la permanencia en lo desbordante. En escena, ese ser trágico no se diferenciaba mucho con el de la tragedia griega, solo que ahora se aferra al destino de un poder mitológico del materialismo que lo engrandece sobre los otros. Actitud del apasionado por el deseo:

En el melancólico la identificación primaria resulta frágil e insuficiente para asegurar el resto de las identificaciones simbólicas a partir de las cuales la Cosa erótica es susceptible de convertirse en un objeto de deseo cautivado y asegurando la continuidad de la metonimia del placer (Kristeva, 1997, p. 18).

Pero en el instante en el que el objeto de deseo desaparece, desaparece lo nombrado; en este sentido, la manera de representar esa pérdida desencadena una serie de reelaboraciones del signo que lo hacen incierto. La cosa permanece en nosotros como símbolo de deseo: "La cosa se inscribe en nosotros sin memoria, cómplice subterránea 
de nuestras angustias indecibles" (Kristeva, 1997, p. 19). Es la identificación de la cosa como permanente en la interioridad la que consigue la caída del déspota.

Se constituye un mundo bajo esta mirada; el materialismo histórico se olvida inevitablemente del otro, sin mirar atrás para pensar el presente y darse cuenta del teatro de la muerte que constituye la historia. En efecto, existe un tránsito de muerte entre la permanencia en el poder por parte del soberano y el derrocamiento con la muerte de este. El objeto deseado por el que tiene el poder y ante su posible pérdida lo proyecta como un agente de violencia mítica, pues antes de ser desvelada, este, invadido por la envidia (del latín invidia: "con la mirada arroja maleficio a los otros"), ataca al otro y consigue llenar las calles de cadáveres. Antes de su caída, el soberano pone en escena su amor por el trono y convierte su permanencia en una amenaza para los otros.

Así, después de haber visto la solemnidad de la figura de poder, ahora es indispensable ver cómo se enfrenta al otro y queda en evidencia la meditación, no como un estado divino de sabiduría, sino como una actitud de luto y mítica proveniente del abismo:

Tiembla frente a su propia espada [...], nunca puede estar tan tranquilo como los que confían su cuerpo a la dura tierra. Aun si se le concede un breve sueño, Morfeo le asalta y le pinta durante la noche con sombrías imágenes sus pensamientos diurnos, aterrorizándole [...] con el sufrimiento y la muerte y con la usurpación de su corona (Gryphius, citado en Benjamin, 1990, pp. 135-136).

\section{La muerte: de la pérdida a la caída}

Resplandecen los pálidos cadáveres, $y$ es cosa del tirano abastecer de ellos al Trauerspiel.

Benjamin, 1990, p. 215

Pensar la caída es comprender que se está en una lucha por la supervivencia; recuperar en cierta medida algo anterior desconocido en nuestra "condición humana" y de lo cual no se tiene referente es redireccionar la lucha por recuperar un estado previo a la caída. La única manera de poder enfrentarse a ese destino de la marginación es en una lucha por aquello que se desconoce, por una redención, la cual siempre terminará con la muerte. Esta condición instituye comportamientos en torno a este conducir 
a la muerte. Se llega a ella inevitablemente de dos maneras: por nuestra condición de caídos y por redención.

La muerte adquiere un propósito dual: el primero es el de la representación alegórica que constituye la muerte del déspota como un acceder al cadáver, no rumbo a la inmortalidad, sino que esa inmortalidad se encuentra en el mundo desalojado de la distancia del melancólico. Esta distancia se puede asociar con el segundo propósito: la lectura del soberano, ya que asume la producción de cadáveres como forma de vida que por el contrario, al acabar la vida del tirano - sin que ello implique usurpar el trono por acción redentora-, mata y muere por una violencia anterior a la instituida en el derecho, la del que se redime a sí mismo, violencia divina: justicia.

El Trauerspiel nos permite ver cómo se redime el objeto de deseo por parte del tirano, cuando esos otros, en el caso Hamlet, le dan muerte por justicia y no por adueñarse del poder; una redención del sí mismo, para este caso, consigue también la del padre asesinado, lo extrae de su condición de cadáver. El arrojo al proyecto de la cosa, por parte del tirano, al estar ahí, implícita, es pulsión de vida, motor que dirige a un punto vital; pero al mismo tiempo aísla, momento en el cual queda excluido todo signo, pérdida, caída, “pulsión de muerte” (Kristeva, 1997).

Ahora redención, sacrificio de sí mismo por el otro, es actuar. El tirano no-actúa, pues vive en la ley del destino y solo se sacrifica en virtud del objeto deseado. El Trauerspiel lo demuestra con la figura de poder. Al rey se le ha asignado un deber divino en un cuerpo humano susceptible a la muerte:

Lo que hace del monarca el personaje central del Trauerspiel no es su enfrentamiento a Dios y con el destino o la actualización de un pasado inmemorial que constituye la clave de una comunidad nacional viva, sino el hecho de que en su figura se ponen a prueba las virtudes de los príncipes y se representan sus vicios, demostrando un profundo conocimiento de la actitud diplomática y una destreza en todo tipo de maquinaciones políticas (Benjamin, 1990, p. 48).

En consecuencia, el melancólico habita una época barroca que expone elementos pseudoantiguos que simulan una condición imperecedera; los libros para esta época son una especie de proyección al infinito. En el cuadro de Durero se ve que los objetos adquieren un carácter fundamental - la importancia del universo- para el 
Renacimiento. Igualmente, al observar la París construida en el siglo XIX se puede denotar que su estructura expone una pseudoantigüedad existente en la nueva ciudad clásica que oculta la ciudad medieval, en ruinas sepultadas y que solo muestra la fragilidad ante la muerte. La ciudad es inmortal en la melancolía. Esta relación contradictoria de la técnica y su aplicación es un diálogo violento -fetiche- que va a esculpir un vínculo conflictivo entre lo que es cotidiano -contenido de misticismo-y lo lejano que, por ejemplo, en el luteranismo extrae lo místico con el fin de superar la simplicidad.

La técnica es la necesidad de poder pensarse fuera de un campo de cadáveres, es un a priori de la historia, contenida en el tiempo y en las acciones del hombre; por consiguiente, escapar de lo simple es encontrar otras posibilidades de pensar el mundo. La economía adquiere tal magnitud al lograr, como afirmó Marx, que la infraestructura avance más rápido que la superestructura. Fischer (1932) lo expone de la siguiente forma:

El mismo espíritu que construye los sistemas filosóficos en el cerebro de los filósofos es el que construye ferrocarriles con las manos de los trabajadores [...] En el desierto del siglo XIX, la técnica, según Marx, es el único ámbito vital en el que el hombre se mueve en medio de una cosa (citado en Benjamin, 2005, p. 667).

Benjamin, en "Teorías del fascismo alemán", revela una relación contradictoria entre técnica y sociedad, una dialéctica de la violencia, del cómo maniobra la una en relación con la otra. La técnica y sus fuentes no encuentran un manejo adecuado y provechoso en la vida cotidiana, aunque los empoderados fuerzan su justificación al negar una interacción armónica, y esto se explica con el hecho de que la guerra, al devastar con sus aviones y armas, evidencia que "la sociedad no estaba lo suficientemente preparada para integrar la técnica como órgano" (Benjamin, 2007b, p. 201).

A su vez, la técnica no podía tampoco someter a las fuerzas sociales; por ende, aparece un río de cadáveres en las calles de la ciudad destruida. Su condición económica se desenvuelve al tomar distancia de lo que en realidad puede constituirse moralmente. La sociedad burguesa aparta a la técnica de lo espiritual desde lo económico, la separa de la codeterminación social. Así, toda rebelión será un inevitable rechazo a la técnica (Benjamin, 2007b). 
El poder de acción sobre las cosas se encuentra en un nivel superior al de otras épocas y se ha transformado de tal manera en la técnica, que consigue transformar los significados del propio arte. A esto conducen los replanteamientos del capitalismo, que, por ejemplo, al aplicar su modelo en la técnica, no deja ver otra cosa que la pérdida del aura de la obra de arte. Este modelo de la reproductibilidad técnica del objeto evidencia que se han olvidado "conceptos heredados [...] como creación y genialidad, perennidad y misterio” (Benjamin, 2007c, p. 148). La obra de arte es susceptible de ser reproducida, y más aún en la época moderna, al contrario de otros tiempos en los que, por ejemplo, los griegos solo podían reproducir monedas con la técnica del fundir y acuñar.

Sucede lo mismo con el dibujo y con la imprenta que consigue reproducir obras escritas. "El ojo es más rápido que la mano dibujando; por eso se ha apresurado enormemente el proceso de la reproducción plástica, que ya pudo ir al paso de la palabra hablada" (Benjamin, 2007c, p. 149). Este arte de la reproducción se puede encontrar fácilmente en el cine, el cual es reproducción en esencia. Cuando se quiere detallar partes de una obra que no se pueden encontrar con facilidad a simple vista, la reproductibilidad técnica posibilita concentrarse en un punto determinado de la obra; decididamente actúa sobre ella, violenta su aquí y ahora; en realidad, en cada momento, velamos por apropiarnos del objeto en su reproductibilidad. Se gesta una conciencia de realidad en las masas a través de la imagen, y es así como surge la novedad por lo inmediato.

La técnica muestra la naturaleza desde un nuevo aspecto, se acerca a los hombres y logra modificar sus miedos y deseos más originarios, pero estos se develan de forma fantasmagórica, como las fotografías viejas. Todo adquiere un valor desde lo olvidado. Esto suele ejercer violencia sobre el individuo. Ahora, el cine, aquel que ha podido mover las masas, también cumple un fin político en el que el arte opera como estallido revolucionario, no como revolución de un arte específico, sino revolucionario en el sentido más general.

Pero este, adicionalmente, es kitsch, arte con carácter de uso, que tiene como lugar especial el cine y, en definitiva, la posibilidad de llevar adelante proyectos que contienen a su vez la esencia de la técnica: "En ella vive también el otro momento: el que pone en acción fines ajenos a la naturaleza con medio(s) igualmente ajenos a ella, hostiles a ella, que se emancipan de ella y la someten" (Benjamin, 2005, p. 401). 
Benjamin, en "Alegoría y Trauerspiel" expone la relación entre alegoría y valor artístico: una obra no se puede remitir únicamente al dominio de un concepto y acomodarse a un modelo preestablecido o, por el contrario, hacer uso de la alegoría para adquirir un valor. La obra se encuentra supeditada a dos funciones: "A la expresión de un concepto y a la expresión de una idea" (Benjamin, 1990, p. 154). Conseguir esta última es lo complicado; que la alegoría se ubique fuera del concepto no quiere decir que exprese una idea auténtica. Solo actúa en forma de inscripción al igual que los jeroglíficos; un cuadro alegórico suscita una gran impresión, pero esa sensación puede causarla también una inscripción.

Esta apreciación permanece durante siglos; aun en Kant se puede observar en su exposición sobre lo bello y lo sublime. Lo estético se encuentra en unos límites que no pueden ser rebasados, exactamente, de forma presente, donde lo bello pasa a un nivel de elevación tal que genera el sentimiento de lo sublime, pero que, al mismo tiempo, al manifestarse lo ausente de eso bello destruye el efecto estético. Esto ausente constituye lo siniestro; lo sostiene Freud citando a Schelling: "lo siniestro es todo aquello que debiendo permanecer oculto se ha revelado"; instante en el que se destruye la máscara de lo bello y se devela como un arte lleno de deseos esculpidos en la soledad, que al salir a la luz, frente a los otros, resultan ser reproducciones de objetos sin aura.

Permanecer en el aura es mirar hacia atrás, al igual que el Ángelus novus de Klee, actuando en la medida en que construimos historia, no de forma lineal, sino reconociendo que hay elementos fundacionales que nos constituyeron en el pasado y que pueden permitir un futuro libre de violencia. De ahí que sea necesario estructurar una forma de existencia que resista a esos avatares en los que se ha ocultado la verdadera historia. 


\section{Condición utópica: por una dialéctica de la resistencia}

Tiene los ojos desencajados, la boca abierta y las alas tendidas. El ángel de la historia debe tener ese aspecto, su cara está vuelta hacia el pasado...

Benjamin, 2007a, p. 67

Es claro que la única manera en que la historia lineal se pone en evidencia, en tanto historia de los vencedores, se da en la resistencia de los otros, que exigen mirar hacia el pasado y reconocerse como víctimas de los cambios generados por las condiciones del poder en manos de unos pocos. Al parecer, no podemos escapar de la violencia y pasamos por encima del otro en el dominio de un poder pasajero, creyéndolo imperecedero. Por el contrario, un reconocimiento de lo anterior exige un replanteo de la mirada, de la "condición humana" de la violencia. Esto implica actuar permanentemente con una conciencia de la cotidianidad, del mundo históricamente monádico que no olvida el pasado al pensar fuerzas indivisibles que también forman parte del todo y que se encuentran más allá de lo objetual, ocultas, sepultadas -los derrotados de la historia-.

En el recorrido del presente artículo se ha podido observar que los distintos momentos conducen al reconocimiento de una historia regida por la violencia; es inevitable entrelazar cierta actitud individual generadora de violencia que oprime al otro y lo sacrifica. Ahora bien, es conveniente pasar a un desarrollo sobre lo que representa la violencia, su forma elemental en la violencia mítica; pero, asimismo, cómo esta se pone en evidencia a través de la resistencia del otro, no en la violencia mítica sino con una violencia divina redentora del hombre en sí mismo, por su dignidad y su derecho a existir.

La historia de la violencia se ha legitimado en el empleo de medios que han caído en contradicción al ser evaluados a la luz de sus fines, sin mayor relevancia a si son justos o legales - dentro del devenir la violencia está por encima de la justicia-. La violencia funda el derecho que a su vez prohíbe la violencia. Este se reserva todo poder sobre ella. Ningún agente externo al derecho puede ejercerla como medio para fines particulares, pues estos no son los del Estado de derecho. Por el contrario, esta violencia fuera del Estado de derecho es la de los otros, la cual es incierta y en la 
revolución descubre el fundamento del derecho, al mostrar que se ha reservado la libertad para hacer violencia.

El Estado de derecho queda desnudo al conseguir someter al otro; por tanto, el Estado, para no verse violento, posibilita, dentro de la ley, el derecho a la huelga (a la resistencia). Así, la huelga y el Estado tienen derecho a la violencia, pero al realizarse esta acción, la huelga revolucionaria consigue quitar el poder al derecho. En consecuencia, el Estado responde con violencia y destruye al otro para evitar tal pérdida.

Esto se ve claramente en la "lucha de clases", que es la disputa por lo material manifestado en su forma más elemental (Marx), y en la cual queda excluido lo espiritual; pero esto, momentáneamente, se encuentra inmerso en dicha lucha cuando los otros dejan ver ese contenido de esperanza que los motiva, por ejemplo, la valentía, la fuerza, es decir, en la resistencia al opresor que tiene el poder. Ahora bien, existe un vínculo implícito con la intensificación melancólica de los poderosos como eje fundamental de su dominio - pensarla en un sentido de atracción y alejamiento sería lo cotidiano frente al objeto- - El poder representado en un hombre escapa de lo simple, tranquilo a una escena exterior a lo cotidiano. Cuando pensamos la historia dominada bajo ese esquema de materialismo histórico, encontramos que se ha hecho lineal-radical y no reconoce sus falencias, ya que ni siquiera las identifica.

Benjamin nos explica que la observación del que ha escrito la historia, como un alguien que alcanzó la victoria, sostiene a este materialismo histórico en la idea de "patrimonio cultural" (Benjamin, 2007a), lo cual es una narración de la barbarie, de los que fueron olvidados por la derrota, documentos de la cultura plasmados por genios y por la esclavitud de los innombrables. Por este motivo es fundamental entender el pasado como algo que nos va a permitir realmente desprendernos de ese materialismo histórico y ahondar en el mesianismo, que desentierra el pasado para comprender lo venidero. El despertar es la instancia ejemplar del rememorar, el surgimiento de la conciencia despierta. "La oscuridad del momento vivido, un saber aún no consciente de lo que ha sido y su resurgimiento tiene la estructura de un despertar" (Bloch, citado en Benjamin, 2005, p. 394).

Contraponer la violencia mítica -estado de frenesí que conduce a la muerte-con una violencia divina es hacer un tránsito hacia un "componente utópico" que permitirá al hombre pensar un estado de no-violencia. Benjamin expone el fundamento del derecho en la violencia, lo que quiere decir que el derecho en sí no puede abandonar 
esa violencia, y cualquier acuerdo o pacto pacífico conducirá irremediablemente a la violencia, pues el acuerdo la contiene instituida en caso de incumplimiento de alguna de las partes. El contrato es de origen violento. Y en estos acuerdos se establece la técnica como mediadora, medio de coerción que obliga al cumplimiento de la norma. Incluso una técnica civil de no agresión terminaría dominada por la mentira y la impunidad por la falta de confianza, porque al prohibirse mentir y engañar en un acuerdo, consigue que al hacerlo se responda con violencia, lo cual imposibilita la manifestación de un medio puro. Este medio es el de la no-violencia.

El derecho a la huelga es un medio puro que de "cierta manera" redime, ya que existen dos modalidades que, al igual que en el Trauerspiel, manifiestan distintas formas de muerte - violencia-: la primera, la huelga general con fines políticos, es un medio que solo utiliza la violencia para alcanzar privilegios poseídos por un poderoso, y consiste en arrebatarle el objeto de deseo. Este tipo de huelga evidencia únicamente un cambio que, con el pasar de las horas, después de haber sido alcanzado el poder, restablece el Estado de derecho. Un ejemplo claro son los golpes militares que en algunas ocasiones son apoyados por el pueblo; pero estos, al derrocar al presidente, asumen la jefatura del Estado aún con más represión en pro del poder conseguido. Se da un simple cambio del grupo dominante.

Estas revoluciones parcializadas no dejan ver otra cosa que la intención del poder, están organizadas de tal manera que aparentan ser dirigidas por los otros, pero lo que en realidad quieren es el objeto de deseo. Benjamin pone el ejemplo de la huelga de los médicos que por unas monedas sacrifican al enfermo y le entregan a la muerte; en la distancia ubican sus conocimientos, procedentes del abismo al ser utilizados para redimir un salario. Por otra parte, existe la huelga revolucionaria, la de la resistencia, que no tiene interés de alcanzar la dirigencia sino solo la de destituir el derecho; no desean los salarios ni los beneficios, pues no están dispuestos a un cambio de amo. Como único objetivo tienen la destrucción del poder del Estado. Despertar del sueño en el que se ha sumergido la vida. Por eso el despertar venidero "está en el caballo de madera de los griegos, en la Troya de lo onírico" (Benjamin, 2005, p. 397):

La huelga general [proletaria] muestra claramente su indiferencia respecto de las ventajas materiales de la conquista, en cuanto declara querer suprimir el Estado; y el Estado era precisamente [...] la razón de ser de los grupos dominantes, que sacan provecho de todas las empresas de las que el conjunto de la sociedad debe soportar los gastos (Benjamin, 2007d, pp. 128-129). 
De esta manera, la segunda forma de huelga es un medio puro de no-violencia, pues no tiene la intención de retomar el poder, se resiste a entrar al círculo de poder que instituye a los dirigentes de turno que oprimen al otro desde el empoderamiento del "trono". Ahora no se piensa en retomar el trabajo bajo condiciones estatales, ya que conducen a un pacto que terminará en violencia con el incumplimiento. Lo que se pretende es llegar al trabajo, a laborar en condiciones no impuestas por el Estado, por tanto, una anarquía que se encuentra antes de la fundación del derecho, en una condición utópica, que en la mayoría de los casos se logra exclusivamente con la muerte.

\section{Conclusión}

La vida se nos ha convertido en un resistir al autómata que gana siempre la partida de ajedrez con un movimiento genial dominado, como dice Benjamin, por un jorobado que lo maneja desde su interior. La historia consiste en actuar y responder a estas jugadas que domina el materialismo histórico. Por ello, "la última conflagración [el siglo XX y lo que lleva del XXI] ha mostrado cómo la desorganización instaurada por la guerra imperialista amenaza con hacerla inconclusa, interminable (Benjamin, 2007b, p. 203).

La existencia tiene como fin la muerte. Lo relevante es el medio que empleemos para llegar a ella, la actitud que asumamos frente al otro y frente a lo que nos rodea. Para el caso del proyecto de Benjamin es el de llegar de la forma más digna, justa y redentora, pues la historia emitirá un juicio y juzgará - no en el derecho-. Este es el juicio final que redimirá o condenará a sus actores, los otros y el jorobado, respectivamente. Los medios utilizados - el existir son una dialéctica que, por lo general, entra en contradicción, la "condición humana", pero que en la resistencia lucha contra sí misma, contra su naturaleza.

Permanecer inactivos y pensar que vivimos en el mejor de los mundos posibles, como pensaba Leibniz, es entregar el mundo al destino y no ejercer sobre él ningún cambio. Asimismo, asumir una actitud pesimista que juzgue a Dios por los dolores del mundo es adentrarse de la misma manera en el mito, en un no-actuar que solo espera a que ese dios cambie de opinión. Así pues, el juicio, ya nombrado en la introducción, tiene como característica ser la palabra juzgadora, símbolo de la caída y desaparición de una comunicabilidad concreta del nombre. Ahora el lenguaje “cayó 
en el abismo de la mediatización de toda comunicación de la palabra como medio, de la palabra vana: en el abismo de la charla" (Benjamin, 2007e, p. 105).

Finalmente, lo que se propone, en parte, el proyecto de Benjamin es el de realizar una deconstrucción que renombre nuestra "condición humana”, caída en un lenguaje que se adentró en la definición del bien y del mal, olvidando su condición original de nombre puro. El lenguaje queda reducido a simple mediador, que a su vez somete la cosa a la locura, en una ensoñación al abandonar el espíritu puro lingüístico de la bienaventuranza. El objetivo es despertar del olvido colectivo de los universalismos y reconocer la necesidad del cambio a una filosofía de la historia de la redención. En estos tiempos, quizá, no se puede vivir la cotidianidad sin antes haber iniciado una búsqueda utópica del tiempo perdido, esto es, entrar en diálogo con la resistencia.

\section{Referencias}

Benjamin, W. (1990). El origen del drama barroco. Madrid: Taurus.

Benjamin, W. (2006). El libro de los pasajes. Madrid: Akal.

Benjamin, W. (2007a). Sobre el concepto de la historia. En Conceptos de filosofía de la historia. Buenos Aires: Terramar.

Benjamin, W. (2007b). Teorías del fascismo alemán. En Conceptos de filosofía de la historia. Buenos Aires: Terramar.

Benjamin, W. (2007c). La obra de arte en la época de su reproductibilidad técnica. En Conceptos de filosofía de la historia. Buenos Aires: Terramar.

Benjamin, W. (2007d). Para una crítica de la violencia. En Conceptos de filosofía de la historia. Buenos Aires: Terramar.

Benjamin, W. (2007e). Sobre el lenguaje en general y sobre el lenguaje de los hombres. En Conceptos de filosofía de la historia. Buenos Aires: Terramar.

Buck-Morss, S. (1989). Dialéctica de la mirada. Walter Benjamin y el proyecto de los Pasajes. Madrid: Visor.

Kant, I. (2003). Crítica de la razón pura. México: Taurus.

Klibansky, R. et ál. (1991). Saturno y la melancolía. Madrid: Alianza. 
Kristeva, J. (1997). Sol negro. Melancolía y represión. Caracas: Monte Ávila.

Marx, K. (s.f.). Tesis sobre Feuerbach. Recuperado de http://es.scribd.com/ doc/16343316/Marx-K-Tesis-sobre-Feuerbach-1845 